\title{
Sorafenib controls the epithelial-mesenchymal transition of ovarian cancer cells via EGF and the CD44-HA signaling pathway in a cell type-dependent manner
}

\author{
GA BIN PARK ${ }^{1 *}$, HYUN-SUK KO ${ }^{2 *}$ and DAEJIN KIM ${ }^{2}$ \\ ${ }^{1}$ Department of Biochemistry, Kosin University College of Medicine, Busan 49267; \\ ${ }^{2}$ Department of Anatomy, Inje University College of Medicine, Busan 47392, Republic of Korea
}

Received February 24, 2016; Accepted February 14, 2017

DOI: $10.3892 / \mathrm{mmr} .2017 .6773$

\begin{abstract}
Cluster of differentiation (CD) 44 and epidermal growth factor (EGF) are closely involved in cellular migration and have been used as stem cell markers. Although the hyaluronan (HA)-binding CD44 is responsible for enhanced cellular motility, the mechanism underlying its actions in various cell types and clinical conditions have yet to be elucidated. In the present study, the multikinase inhibitor sorafenib was used to investigate the diverse effects of EGF stimulation on epithelial-mesenchymal transition (EMT) in ovarian cancer cells using immunoblotting and reverse transcription-polymerase chain reaction. In addition, the association between EGF and CD44/HA signaling pathways in the control of mesenchymal phenotype was determined by gene silencing with small interfering RNA transfection. EGF stimulation of ovarian cancer cells increased cellular migration, mesenchymal transition, CD44 expression and the activation of matrix metalloproteinase (MMP)-2 and MMP-9. Sorafenib effectively suppressed the loss of epithelial characteristics in EGF-treated SK-OV-3 ovarian cancer cells, via targeting the mitogen-activated protein kinase (MAPK)/extracellular signal-regulated kinase (ERK) pathway. Although treatment of Caov-3 ovarian cancer cells with sorafenib blocked the expression of mesenchymal phenotypes following EGF stimulation, EGF-activated Caov-3 cells exhibited reduced MAPK/ERK signaling. Furthermore, EGF-activated Caov-3 cells increased the expression of hyaluronan synthase 2 and HA-CD44 ligation in EGF-exposed Caov-3 cells, which resulted in the activation of the Ras/Raf/MEK signaling
\end{abstract}

Correspondence to: Professor Daejin Kim, Department of Anatomy, Inje University College of Medicine, 75 Bokji-ro, Jin-gu, Busan 47392, Republic of Korea

E-mail:kimdj@inje.ac.kr

*Contributed equally

Key words: epidermal growth factor, CD44, hyaluronan, epithelial-mesenchymal transition, sorafenib, ovarian cancer pathway, amplification of migratory activity and the expression of mesenchymal markers, including $\mathrm{N}$-cadherin and vimentin. Furthermore, silencing EGFR in SK-OV-3 cells and CD44 in Caov-3 cells suppressed their migratory activity, through inhibition of the MAPK/ERK pathway. The present results suggested that EGF-mediated signaling may regulate metastasis and invasion of ovarian cancer cells, in a cancer cell type-dependent manner.

\section{Introduction}

Recurrent or residual cancer cells that persist following treatment with anticancer drugs possess the characteristics of cancer stem cells and an epithelial-mesenchymal transition (EMT) phenotype (1). Ovarian cancer is a major cause of gynecological cancer-associated mortality worldwide (2). Although radical surgery and platinum- and taxane-based adjuvant chemotherapy can achieve progression-free survival in $~ 50 \%$ of patients, the majority will relapse eventually (3). In ovarian cancer, tumor cells undergo EMT, which is accompanied by invasive growth and metastasis (4). Therefore, the inhibition of EMT may have potential as a therapeutic strategy aiming to control ovarian carcinogenesis and improve the outcome of anticancer treatments.

Epidermal growth factor (EGF) -related growth factors and their cognate receptors are widely recognized as key autocrine regulators implicated in the control of cancer cell proliferation, invasion and metastasis (5). EGF contributes to the post-ovulatory proliferation of the ovarian surface epithelium, via binding to the EGF receptor (EGFR) (6), and aberrant EGF/EGFR expression has been reported in ovarian cancer (7). Elevated EGFR levels have been significantly correlated with aggressive disease characteristics (8); however, the molecular mechanisms underlying the actions of EGF in various types of cancer cells and different clinical stages have yet to be elucidated.

Cluster of differentiation (CD) 44 is the principal transmembrane adhesion receptor for hyaluronan (HA) and serves a central role in HA-mediated cellular migration, and cancer cell invasion and metastasis (9). HA-binding CD44 has been reported to decrease the expression of E-cadherin, and increase the expression of Snail, vimentin and N-cadherin (10). The 
interaction between CD44 and EGFR has been implicated in CD44-mediated cellular motility (11), as EGF has been demonstrated to enhance CD44 cleavage and promote cellular motility, through the activation of Rac (12). EGF/EGFR and CD44/HA binding are events commonly associated with the mitogen-activated protein kinase (MAPK)/extracellular signal-regulated kinase (ERK) signaling pathway $(13,14)$. Activation of the MAPK/ERK pathway is common in malignancies and has been reported to drive the proliferation, migration and invasion of cancer cells (15). However, the detailed effects, as well as the interactions of EGF and CD44 during EMT regulation in ovarian cancer have yet to be elucidated.

Sorafenib is a small molecule that inhibits the Raf family of kinases (16), and consequently, the MAPK/ERK pathway in cancer cells (17). The aim of the present study was to investigate the mechanisms underlying the implication of the EGF/EGFR and CD44/HA pathways in cellular migration and invasion using the metastatic SK-OV-3 and the primary Caov-3 ovarian cancer cell lines $(18,19)$. In addition, sorafenib was used to investigate the putative association between the EGF/EGFR and CD44/HA signaling pathways during ovarian cancer metastasis and invasion.

\section{Materials and methods}

Cell culture and reagents. The SK-OV-3 and Caov-3 human ovarian cancer cell lines were obtained from American Type Culture Collection (Manassas, VA, USA). Cells were maintained in Dulbecco's modified Eagle's medium (DMEM; GE Healthcare Bio-Sciences, Pittsburgh, PA, USA) supplemented with $10 \%$ heat-inactivated fetal bovine serum (FBS; HyClone; GE Healthcare Bio-Sciences, Logan, UT, USA), penicillin $(100 \mathrm{U} / \mathrm{ml})$ and streptomycin $(100 \mu \mathrm{g} / \mathrm{ml}$; GE Healthcare Bio-Sciences), and were cultured at $37^{\circ} \mathrm{C}$ in a $5 \% \mathrm{CO}_{2}$ atmosphere. Human recombinant EGF was purchased from BD Biosciences (San Jose, CA, USA). HA was purchased from R\&D Systems, Inc. (Minneapolis, MN, USA). Sorafenib (BAY43-9006, Nexavar ${ }^{\circledR}$ ) was purchased from LC Laboratories (Woburn, MA, USA).

Flow cytometric analysis. For cell cycle analysis, SK-OV-3 and Caov-3 cells were seeded in DMEM containing 10\% FBS with penicillin $(100 \mathrm{U} / \mathrm{ml})$ and streptomycin $(100 \mu \mathrm{g} / \mathrm{ml})$, at a density of $2 \times 10^{5} / 100-\mathrm{mm}$ plate. Following overnight incubation, cells were treated with EGF $(5 \mu \mathrm{M})$ for 45 min and then cultured for $24 \mathrm{~h}$. Cells were harvested, washed with PBS and fixed in $70 \%$ ethanol in PBS at $-20^{\circ} \mathrm{C}$ overnight. Cells were then resuspended in PBS containing $40 \mu \mathrm{g} / \mathrm{ml}$ propidium iodide (PI; Invitrogen; Thermo Fisher Scientific, Inc., Waltham, MA, USA) and $100 \mu \mathrm{g} / \mathrm{ml}$ RNase (Invitrogen; Thermo Fisher Scientific, Inc.), and incubated for $30 \mathrm{~min}$ at $37^{\circ} \mathrm{C}$ in the dark. Cell cycle analysis was performed using a FACSCalibur flow cytometer (BD Biosciences) equipped with CellQuestpro software (version 5.1; BD Biosciences). To investigate alterations in CD44 expression on the cell surface, Caov-3 or SK-OV-3 cells were seeded at a density of $2 \times 10^{5} / 100-\mathrm{mm}$ plate and treated with EGF $(5 \mu \mathrm{M})$ or EGF with sorafenib dissolved in DMSO $(5 \mu \mathrm{M})$ in DMEM containing $10 \%$ FBS. The cells were cultured for $48 \mathrm{~h}$ at $37^{\circ} \mathrm{C}$ prior to analysis by flow cytometry.
Cells were then harvested and stained with an anti-CD44 fluorescein isothiocyanate (FITC)-conjugated antibody (cat. no. \#555478; dilution, 1:50; BD Biosciences) for $30 \mathrm{~min}$ at $4^{\circ} \mathrm{C}$ in the dark. Samples were analyzed using a FACSCalibur flow cytometer (BD Biosciences) equipped with CellQuestpro software (version 5.1; BD Biosciences).

Scratch wound healing assay. SK-OV-3 or Caov-3 cells were seeded into a 6-well plate at a density of $3 \times 10^{5} / 2 \mathrm{ml}$ in DMEM containing $10 \%$ FBS. The confluent cell monolayers were wounded via scratching with a $200-\mu 1$ pipette tip and cells were incubated with EGF $(5 \mu \mathrm{M})$ for $45 \mathrm{~min}$ at $37^{\circ} \mathrm{C}$. After washing with PBS, EGF-treated SK-OV-3 or Caov-3 cells were cultured in the presence or absence of sorafenib $(5 \mu \mathrm{M})$ for $24 \mathrm{~h}$. Images of scratch wounds were captured (10x objective) under an inverted phase contrast microscope following $24 \mathrm{~h}$ of culture. The number of cells that migrated into the scratched area was analyzed using Image J v1.38 software (National Institutes of Health, Bethesda, MD, USA). Each experiment was conducted in triplicate.

Reverse transcription-polymerase chain reaction ( $R T-P C R)$. Total RNA was extracted from SK-OV-3 and Caov-3 cells, including the non-treated control, DMSO-treated, EGF-treated, sorafenib-treated and EGF and sorafenib co-treated groups, using TRIzol ${ }^{\circledR}$, according to the manufacturer's protocol (Invitrogen; Thermo Fisher Scientific, Inc.). The DMSO-treated group was used as a control for the sorafenib-treated group. Briefly, the RNA pellet extracted from each group was washed twice with $1 \mathrm{ml} 75 \%$ ethanol and then dried using a vacuum for $10 \mathrm{~min}$ at room temperature. Pure RNA samples ( $\mu \mathrm{g}$; A260/A280 ratio >1.6) were transcribed into cDNA using the AccuPower RT Premix (cat. no. \#K-2043; $10 \mathrm{mM}$ dNTPs, $2.5 \mathrm{mM}$ of each dNTP; final concentration, $0.5 \mathrm{mM}$; Bioneer Corporation, Daejeon, Korea), oligo (dT) (5 $\mu \mathrm{M})$, RNase inhibitor (cat. no. \#2313A; $10 \mathrm{U} / \mu 1$; Takara Bio, Inc., Otsu, Japan), reverse transcriptase (100 U/ $\mu \mathrm{l}$; Bioneer Corporation) and oligo-dT primers (cat. no. \#N-7053; Bioneer Corporation). PCR was performed according to the manufacturer's instructions using the Prime Taq Premix with Prime Taq DNA Polymerase 1 unit/10 $\mu 1,2 \mathrm{X}$ reaction buffer, $4 \mathrm{mM} \mathrm{MgCl}_{2}$, enzyme stabilizer, sediment, loading dye, $\mathrm{pH} 9.0$ and $0.5 \mathrm{mM}$ each of dATP, dCTP, dGTP, dTTP (cat. no. \#G-3002; GeNet Bio, Daejeon, Korea) with the following primers and Takara PCR Thermal Cycler Dice (cat. no. \#TP600; Takara Bio, Inc.). Initially, the mixed RT product was reacted at $95^{\circ} \mathrm{C}$ for $30 \mathrm{sec}$ for denaturation and then the annealing step was performed with specific primers: Vimentin (30 cycles at $60^{\circ} \mathrm{C}$ ), sense GGAAGAGAACTTTGCCGTTGA A, antisense GTGACGAGCCATTTCCTCCTT; matrix metalloproteinase (MMP)-2 (30 cycles at $66^{\circ} \mathrm{C}$ ), sense TGGCAA GTACGGCTTCTGTC, antisense, TGGCAAGTACGGCTT CTGTC; MMP-9 $\left(25\right.$ cycles at $\left.65^{\circ} \mathrm{C}\right)$, sense TGCGCTACC ACCTCGAACTT, antisense GATGCCATTGACGTCGT CCT; B-Raf $\left(30\right.$ cycles at $\left.58^{\circ} \mathrm{C}\right)$, sense TGGGGAACGGAA CTGATTTTTC, antisense TTTTGTGGTGACTTGGGG TTG; hyaluronan synthase (HAS) $1\left(30\right.$ cycles at $\left.60^{\circ} \mathrm{C}\right)$, sense TACAACCAGAAGTTCCTGGG, antisense CTGGAGGTG TACTTGGTAGC; HAS2 (30 cycles at $\left.60^{\circ} \mathrm{C}\right)$, sense GTGGAT TATGTACAGGTTTGTGA, antisense TCCAACCATGGG 
ATCTTCTT; HAS3 $\left(30\right.$ cycles at $60^{\circ} \mathrm{C}$ ), sense GAGATGTCC AGATCCTCAACAA, antisense CCCACTAATACACTG CACAC; and $\beta$-actin $\left(25\right.$ cycles at $\left.60^{\circ} \mathrm{C}\right)$, sense ATCCAC GAAACTACCTTCAA and antisense ATCCACACGGAG TACTTGC. Extension steps were performed at $72^{\circ} \mathrm{C}$ for $1 \mathrm{~min}$ and the final elongation step was at $72^{\circ} \mathrm{C}$ for $5 \mathrm{~min}$. PCR products were analyzed by agarose gel (1\%) electrophoresis and visualized using ethidium bromide (Sigma Aldrich; Merck KGaA, Darmstadt, Germany) under ultraviolet light using the multiple Gel DOC system (Fujifilm Corporation, Tokyo, Japan). Semi-quantitative analysis of PCR products was performed using Image J v1.38 software (National Institutes of Health, Bethesda, MD, USA). Each experiment was performed at least three times and the results are representative of three independent experiments.

Western blot analysis. The SK-OV-3 or Caov-3 cells, including the non-treated control, DMSO-treated, EGF-treated, sorafenib-treated and EGF and sorafenib co-treated groups, were harvested, lysed in NP-40 cell lysis buffer (Elpis Biotech, Inc., Daejeon, Korea), and total protein was extracted. The DMSO-treated group was used as a control for the sorafenib-treated group. To address phosphorylation events, an additional set of phosphatase inhibitors (Cocktail II; Sigma-Aldrich; Merck KGaA) was added to the NP-40 buffer. Protein concentration was determined using a bicinchoninic assay kit according to the manufacturer's instructions (Pierce; Thermo Fisher Scientific, Inc.). The same volume of 2X Laemmli sample buffer (Elpis Biotech, Inc.) was added to each lysate, and protein (10 $\mu \mathrm{g} / \mathrm{sample})$ was immediately boiled for $5 \mathrm{~min}$ at $100^{\circ} \mathrm{C}$. Equal quantities of protein (10 $\mu \mathrm{g} / \mathrm{lane})$ were separated using 8 to $12 \%$ SDS-PAGE at $100 \mathrm{~V}$ for $1 \mathrm{~h}$, then transferred to nitrocellulose membranes (Merck Millipore; Merck KGaA) at $340 \mathrm{~mA}$ for $2 \mathrm{~h}$. Following blocking with 5\% non-fat skim milk for $1 \mathrm{~h}$ at room temperature, primary antibodies against the following proteins were used: EGFR (cat. no. \#2232; dilution, 1:1,000), MMP-2 (cat. no. \#4022; dilution, 1:1,000), MMP-9 (cat. no. \#3852; dilution, 1:1,000), E-cadherin (cat. no. \#3195; dilution, 1:1,000), N-cadherin (cat. no. \#13116; dilution, 1:1,000), vimentin (cat. no. \#5741; dilution, 1:1,000), p50 (cat. no.\#3035; dilution, 1,000)/p65 (cat. no. \#8242; dilution, 1,000) subunits of nuclear factor (NF)- $\mathrm{kB}$, phosphorylated (p)-p38 (Thr180/Tyr182; cat. no. \#9211; dilution, 1:1,000), total p38 (cat. no. \#9212; dilution, 1:1,000), p-c-Jun N-terminal kinase (JNK) (Thr183/Tyr185; cat. no. \#4671; dilution, 1:1,000), total JNK (cat. no. \#9258; dilution, 1:1,000) and $\beta$-actin (cat. no. \#4967; dilution, 1:2,000); all purchased from Cell Signaling Technology, Inc. (Danvers, MA, USA). CD44 (cat. no. \#sc-53298; dilution, 1:500), CD147 (cat. no. \#sc-13976; dilution, 1:500), phosphatidylinositol-4,5-bisphosphate 3-kinase (PI3K) (cat. no. \#sc-1637; dilution, 1:200), p-Akt (Ser473; cat. no. \#sc-33437; dilution, 1:200), total Akt (cat. no. \#sc-81434; dilution, 1:200), p-MAPK/ERK kinase (MEK; Ser218/Ser222; cat. no. \#sc-7995; dilution, 1:500), total MEK (cat. no. \#sc-436; dilution, 1:500), p-ERK (Thr202/Tyr204; cat. no. \#sc-7383; dilution, 1:500), total ERK (cat. no. \#sc-94; dilution, 1:500), pan Ras (cat. no. \#sc-166691; dilution, 1:200) and B-Raf (cat. no. \#sc-136263; dilution, 1:200) were all purchased from Santa Cruz Biotechnology, Inc. (Dallas,
TX, USA). The membrane was probed with primary antibodies overnight at $4^{\circ} \mathrm{C}$, followed by the following specific secondary antibodies: Goat anti-mouse-horseradish peroxidase (HRP; cat. no. \#K0211589; dilution, 1:3,000) or goat anti-rabbit-HRP (cat. no. \#K0211708; dilution, 1:3,000; both KOMABiotech, Seoul, Korea) were incubated for $1 \mathrm{~h}$ at room temperature. The protein bands were visualized using an enhanced chemiluminescence detection kit (Advansta Inc., Menlo Park, CA, USA) and the multiple Gel DOC system (Fujifilm Corporation). $\beta$-actin was used as a loading control. The intensities of protein bands were normalized to those of $\beta$-actin and semi-quantified using Image J v1.38 software (National Institutes of Health).

Immunofluorescence and confocal microscopy. Caov-3 cells were seeded at a density of $3 \times 10^{5} / \mathrm{ml}$ and treated with EGF $(5 \mu \mathrm{M})$ or co-treated with EGF $(5 \mu \mathrm{M})$ and HA $(50 \mu \mathrm{g} / \mathrm{ml})$. Cells were washed with PBS, fixed in $4 \%$ methanol-free formaldehyde (pH 7.4) at $4^{\circ} \mathrm{C}$ for 25 min, followed by blocking with $0.5 \%$ Tween-20 in 5\% bovine serum albumin (Sigma Aldrich; Merck KGaA) in PBS for $1 \mathrm{~h}$ at room temperature. The cells were subsequently incubated with anti-N-cadherin antibody (cat. no. \#sc-7939; dilution, 1: 500; Santa Cruz Biotechnology, Inc.) for $24 \mathrm{~h}$ at room temperature, washed twice with PBS and incubated with FITC-labeled secondary antibody (cat. no. \#F0382; dilution, 1:80; Sigma-Aldrich; Merck KGaA) for $1 \mathrm{~h}$ at room temperature. PI was used as a nuclear stain. Confocal images were obtained using a Zeiss LSM510 confocal microscope and analyzed with the Software Release v2.5 Service Pack 2 for LSM 510 (Carl Zeiss AG, Oberkochen, Germany).

Small interfering (si)RNA transfection. Experimentally verified human CD44-siRNA duplex (5'-AUGUCUUCAGGA UUCGUUCUU-3') and negative control-siRNA (5'-ACGUGA CACGUUCGGAGAATT-3') were obtained from Bioneer Corporation. Experimentally verified human EGFR-siRNA duplex was purchased from Santa Cruz Biotechnology, Inc. (cat. no.\#sc-29301). Cells were seeded at a density of $3 \times 10^{5} /$ well in a 6-well plate and incubated overnight prior to transfection with $200 \mathrm{nM}$ siRNA using Lipofectamine ${ }^{\circledR}$ RNAiMAX Reagent (Invitrogen; Thermo Fisher Scientific, Inc.) according to the manufacturer's protocol. Following transfection with the specific siRNA, the expression levels of CD44 or EGFR were determined by western blot analysis. The cells were used for the scratch wound healing assay and immunoblotting against EGFR, CD44, Ras, B-Raf, p-MAPK/ERK and MEK as described above, to analyze migratory activity and the signaling pathways involved at $48 \mathrm{~h}$ post-transfection.

Statistical analysis. The statistical significance of the difference between non-treated control cells and EGF or EGF with HA-treated cells was assessed by one-way analysis of variance (ANOVA) using SigmaPlot software (version 10.0; Systat Software, Inc., San Jose, CA, USA). Bonferroni post hoc analysis was performed following the ANOVA for multiple comparisons. Data are expressed as the mean \pm standard error of the mean and each value is representative of at least two independent experiments. $\mathrm{P}<0.05$ was considered to indicate a statistically significant difference. 
A

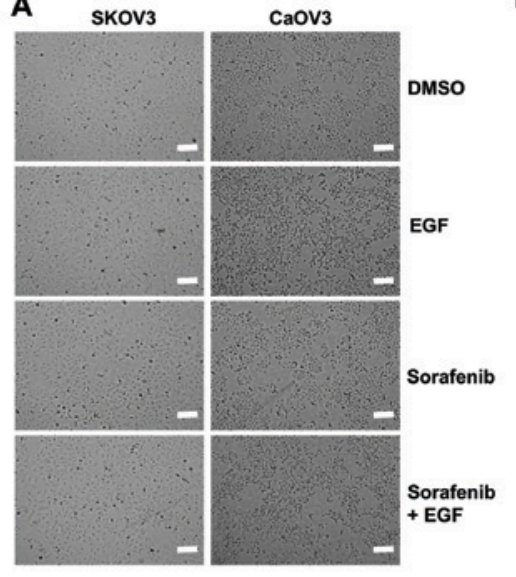

B
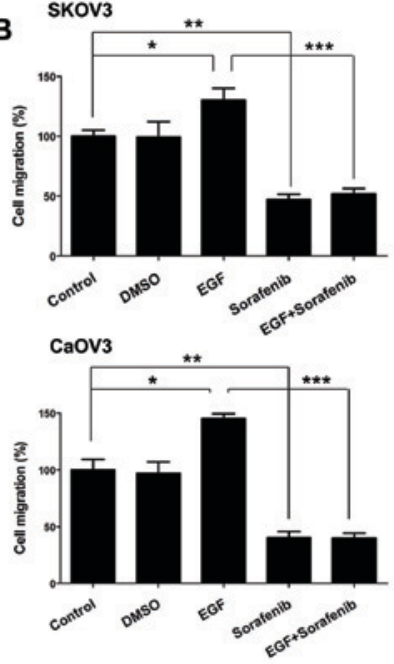

D
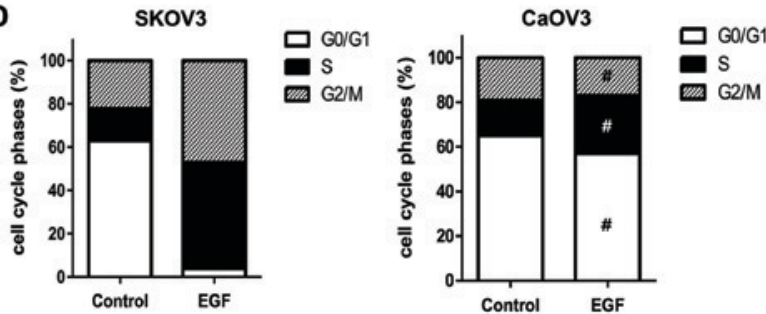

C

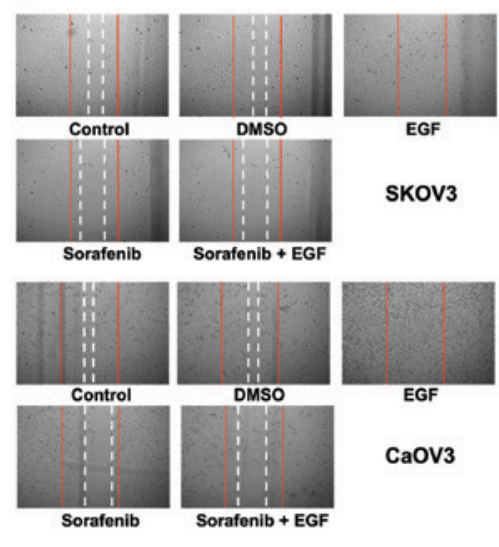

Figure 1. Effects of EGF on cellular migration and cell cycle distribution in SK-OV-3 and Caov-3 cells. (A) Spindle-shaped morphological alterations were induced by EGF treatment. Cell morphology was observed under an inverted phase contrast microscope. Photomicrographs were captured at magnification, x100 using a digital camera. Scale bar, $100 \mu \mathrm{m}$. (B) Cellular motility of EGF-activated cells was measured using a wound healing assay. The migrated distance into the scratched area was calculated and plotted as a percentage of migration. (C) SK-OV-3 and Caov-3 cells were treated with EGF, sorafenib or EGF combined with sorafenib for $24 \mathrm{~h}$. Migratory capabilities were analyzed using a wound healing assay. The images shown are representative of three independent experiments. (D) Effects of EGF on cell cycle distribution, as measured using propidium iodide staining and flow cytometric analysis. Graphs are representative of three independent experiments. Data are expressed as the mean \pm standard error of the mean. ${ }^{*} \mathrm{P}<0.05, \mathrm{Control}$ vs. EGF groups; ${ }^{* *} \mathrm{P}<0.01$, Control vs. Sorafenib groups; ${ }^{* * *} \mathrm{P}<0.001$, EGF group vs. Sorafenib + EGF groups; ${ }^{*} \mathrm{P}<0.01$, EGF-treated SK-OV-3 cells vs. EGF-treated Caov-3 cells. EGF, epidermal growth factor; DMSO, dimethyl sulfoxide.

\section{Results}

EGF stimulates migratory activity and mesenchymal characteristics of ovarian cancer cells. To examine the effects of EGF on ovarian cancer cells, Caov-3 cells, derived from human ovarian primary adenocarcinoma, and SK-OV-3 cells, derived from ovarian cancer malignant ascites, were used $(18,19)$. Following EGF stimulation, the population of ovarian cancer cells with spindle-shaped morphology was increased; however, pretreatment with sorafenib resulted in the maintenance of epithelial cellular characteristics following EGF activation (Fig. 1A). The effects of sorafenib on the migratory capabilities of ovarian cancer cells were examined using a wound healing assay following EGF treatment for $45 \mathrm{~min}$, followed by $24 \mathrm{~h}$ incubation in the presence of sorafenib. The motility of cancer cells was assessed according to the distance traveled into a scratched area. Sorafenib inhibited the migratory activity of EGF-treated SK-OV-3 and Caov-3 cells (Fig. 1B and C). To examine whether the effects of EGF on cancer cell proliferation differed in the two cell types, cell cycle analysis was performed using PI staining. Although Caov-3 cells exhibited a slight increase in the percentage of cells in the $S$ phase following EGF treatment, the proportion of SK-OV-3 cells in the $S$ and $G_{2} / M$ phases was markedly increased following stimulation with EGF (Fig. 1D). These results suggested that
EGF may potentiate the invasive capabilities of ovarian cancer cells, and may employ different signaling mechanisms in each cell line.

EGF stimulation enhances the expression of CD44 and CD147 in Caov-3 cells. The effects of EGF stimulation on the mesenchymal properties of the two cancer cell lines were investigated. The mRNA and protein expression levels of vimentin, MMP-2 and MMP-9 were markedly upregulated in EGF-treated SK-OV-3 and Caov-3 cells (Fig. 2A and B). Conversely, sorafenib inhibited the expression of the mesenchymal marker $\mathrm{N}$-cadherin and enhanced the expression of the epithelial marker E-cadherin (Fig. 2C). Surface EGFR was upregulated following EGF treatment in SK-OV-3 and Caov-3 cells. Notably, EGF appeared to exert no influence on CD44 and CD147 protein levels in SK-OV-3 cells, whereas Caov-3 cells exhibited increased CD44 and CD147 levels following EGF treatment (Fig. 2C). Alterations in CD44 surface expression in EGF-activated cancer cells were also examined using flow cytometry. CD44 levels were upregulated by $~ 40 \%$ in SK-OV-3 cells and by 2.4 -fold in Caov-3 cells following treatment with EGF (Fig. 2D). Sorafenib reduced the expression of EGFR, CD44, CD147 and the p50/p65 NF- $\kappa \mathrm{B}$ subunits (Fig. 2C). These results suggested that ovarian cancer cell motility could be differentially controlled by EGF/EGFR 
A

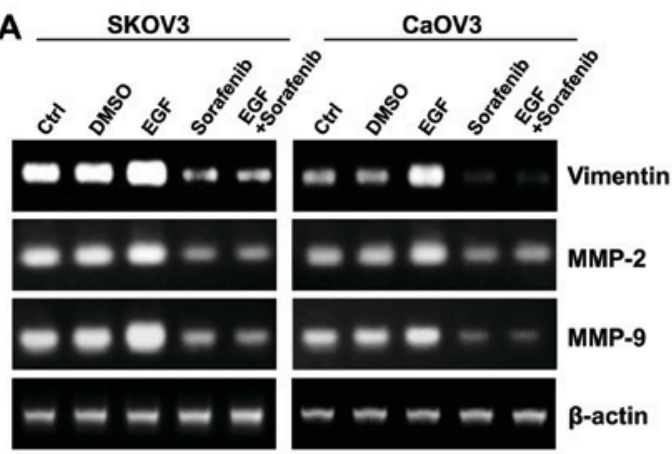

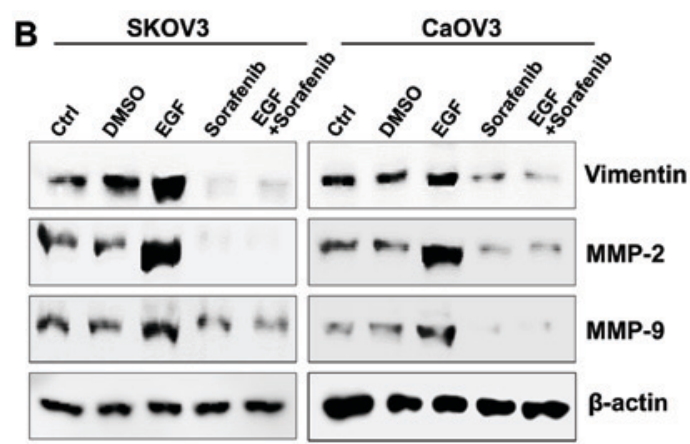
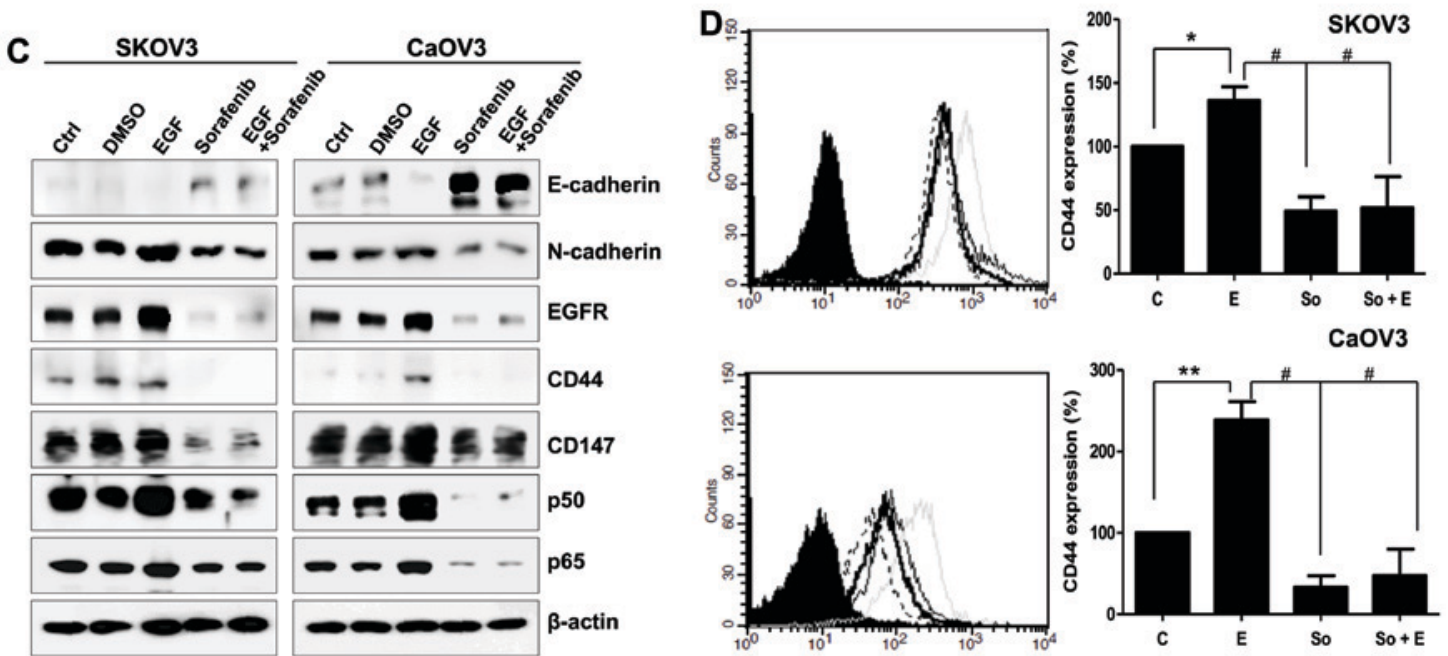

Figure 2. Mesenchymal phenotype of SK-OV-3 and Caov-3 cells elicited by EGF stimulation. (A) mRNA and (B) protein expression levels of vimentin, MMP-2 and MMP-9 in EGF-treated ovarian cancer cells. (C) E-cadherin, N-cadherin, EGFR, CD44, CD147 and p50/p65 NF- $\mathrm{BB}$ subunit expression was assessed using western blot analysis in EGF-stimulated SK-OV-3 and Caov-3 cells. $\beta$-actin served as an internal control. (D) Flow cytometric analysis revealed the alterations in CD44 expression following treatment with EGF or EGF and sorafenib in ovarian cancer cells. C, thin black line; E, gray line; So, dotted-line; $\mathrm{E}+$ So, thick black line. Data are expressed as the mean \pm standard error of the mean. ${ }^{*} \mathrm{P}<0.05$ and ${ }^{* *} \mathrm{P}<0.01, \mathrm{EGF}$ group vs. Control group; ${ }^{*} \mathrm{P}<0.01, \mathrm{EGF}$ group or EGF-treated group vs. Sorafenib. C, control group; D, DMSO group; E, EGF-treated group; So, sorafenib-treated group; So + E, sorafenib- and EGF-treated group; EGF, epidermal growth factor; MMP, matrix metalloproteinase; EGFR, EGF receptor; CD, cluster of differentiation; NF, nuclear factor.

signaling in a cell type-specific manner; however, sorafenib appeared to interfere in EMT processes in both cancer cell types.

Sorafenib regulates the motility of EGF-activated Caov-3 cells through the activation of HAS2. EGF-activated Caov-3 cells exhibited enhanced CD147 expression (Fig. 2). CD147 is a multifunctional glycoprotein located in the cell membrane, which is highly expressed on cancer cells (20). CD147 has been reported to induce synthesis of the large extracellular polysaccharide HA, the main ligand for the cell-surface receptor CD44 (21). CD147-induced CD44/HA interactions have been implicated in various signaling pathways and may potentiate tumorigenic properties in various cancer cells (22). The present study investigated the effects of EGF on HA production in ovarian cancer cells. The mRNA expression levels of the hyaluronan synthases HAS1, HAS2 and HAS3 were determined using RT-PCR. HAS1 mRNA expression levels appeared unaffected in SK-OV-3 and Caov-3 cells regardless of the treatment applied, whereas HAS3 mRNA levels decreased following treatment with sorafenib (Fig. 3A). Notably, HAS2 mRNA levels were markedly upregulated following EGF stimulation, whereas this effect was abolished by sorafenib in
Caov-3 cells (Fig. 3A). Therefore, the present study examined whether upregulated CD44 may trigger cell migration more effectively via ligation with HA. HA treatment appeared to slightly increase the migratory activity of non-EGF-activated SK-OV-3 cells; however, co-treatment with EGF and HA had no additional effect on cellular motility (Fig. 3B). The invasive activity of Caov-3 cells was significantly enhanced following combined treatment with EGF and HA (Fig. 3C). These results suggested that CD44 stimulation, acting via a HA-HAS2 mediated pathway, may potentiate the EGF-induced migration and invasion of Caov-3 cells.

CD44/HA-dependent MAPK/ERK pathway controls the migration and invasion of Caov-3 cells. EGF/EGFR signaling varied between SK-OV-3 and Caov-3 cells, and involved HAS activation and HA-mediated cellular migration, whereas sorafenib markedly inhibited the migratory capabilities of EGF- and HA-stimulated ovarian cancer cells (Fig. 3B and C). The molecular mechanism underlying the actions of sorafenib on cellular migration was investigated in SK-OV-3 and Caov-3 cells. Sorafenib has been reported to target the Raf- 1 and B-Raf kinases that form part of the MAPK/ERK pathway (16). B-Raf mRNA expression levels in EGF-stimulated SK-OV-3 
cells appeared to be increased, along with protein levels of the Raf-related signaling molecules Ras and p-MEK, i.e., activated MEK (Fig. 4A and B). Furthermore, EGF treatment suppressed the mRNA expression levels of B-Raf in Caov-3 cells (Fig. 4A); the EGF-activated MAPK/ERK signaling pathway also appeared to be inhibited in Caov-3 cells (Fig. 4B). In addition, p-MAPKs, including p38, ERK and JNK, were downregulated in EGF-stimulated Caov-3, but not SK-OV-3, cells (Fig. 4C). Although the expression of Raf in EGF-stimulated Caov-3 cells appeared downregulated, sorafenib effectively prevented cellular migration and the appearance of mesenchymal phenotype.

To identify the mechanism underlying Caov-3 migration following treatment with EGF, the effects of HA treatment on the MAPK/ERK signaling pathway were examined in EGF-activated Caov-3 cells. The combined treatment of SK-OV-3 cells with EGF and HA exerted no significant effect on the MAPK/ERK signaling pathway, compared with in cells treated with EGF alone (Fig. 5A). Conversely, the EGF/HA combined treatment considerably enhanced the expression of MAPK/ERK kinases in Caov-3 cells compared with in cells treated with EGF alone. In addition, treatment of EGF/HA-co-stimulated Caov-3 cells with sorafenib attenuated activation of the MAPK/ERK signaling pathway (Fig. 5B). These results suggested that CD44 stimulation by HA may be associated with the MAPK/ERK signaling pathway in EGF-stimulated Caov-3 cells.

EGF/HA combined treatment potentiates the mesenchymal properties of ovarian cancer cells. The effects of HA treatment on the expression of mesenchymal properties in EGF-stimulated SK-OV-3 and Caov-3 cells were examined. Stimulation with HA enhanced the expression of the mesenchymal markers $\mathrm{N}$-cadherin and vimentin, and of the p50/p65 $\mathrm{NF}-\kappa \mathrm{B}$ subunits, whereas it inhibited the expression of the epithelial marker E-cadherin in EGF-activated SK-OV-3 and Caov-3 cells (Fig. 6A). There were no significant differences in the expression of signaling molecules between EGF-treated, and EGF and HA-treated SK-OV-3 cells (Fig. 5A). In addition, EGF treatment combined with HA activated the MAPK/ERK signaling pathway in Caov-3 cells when compared with the group stimulated with EGF alone (Fig. 5B). Therefore, the present study examined whether combined treatment of EGF with HA enhanced the expression of mesenchymal markers in Caov-3. Immunofluorescence was used to observe the increased N-cadherin levels in EGF-treated Caov-3 cells following HA treatment, compared with cells treated with EGF alone. Conversely, the expression of N-cadherin was downregulated following treatment with sorafenib in HA-treated and non-treated EGF-activated SK-OV-3 and Caov-3 cells (Fig. 6A and B). These results suggested that CD44/HA activation may be implicated in EMT induction in EGF-activated ovarian cancer cells.

EGFR in SK-OV-3 and CD44 in Caov-3 cells promote EMT through activation of the MAPK/ERK pathway. The roles of EGF in SK-OV-3 and of CD44 in Caov-3 cells in activation of the MAPK/ERK signaling pathway were investigated during EMT. EGFR silencing via RNA interference resulted in a decrease in the migratory activity of SK-OV-3 cells compared
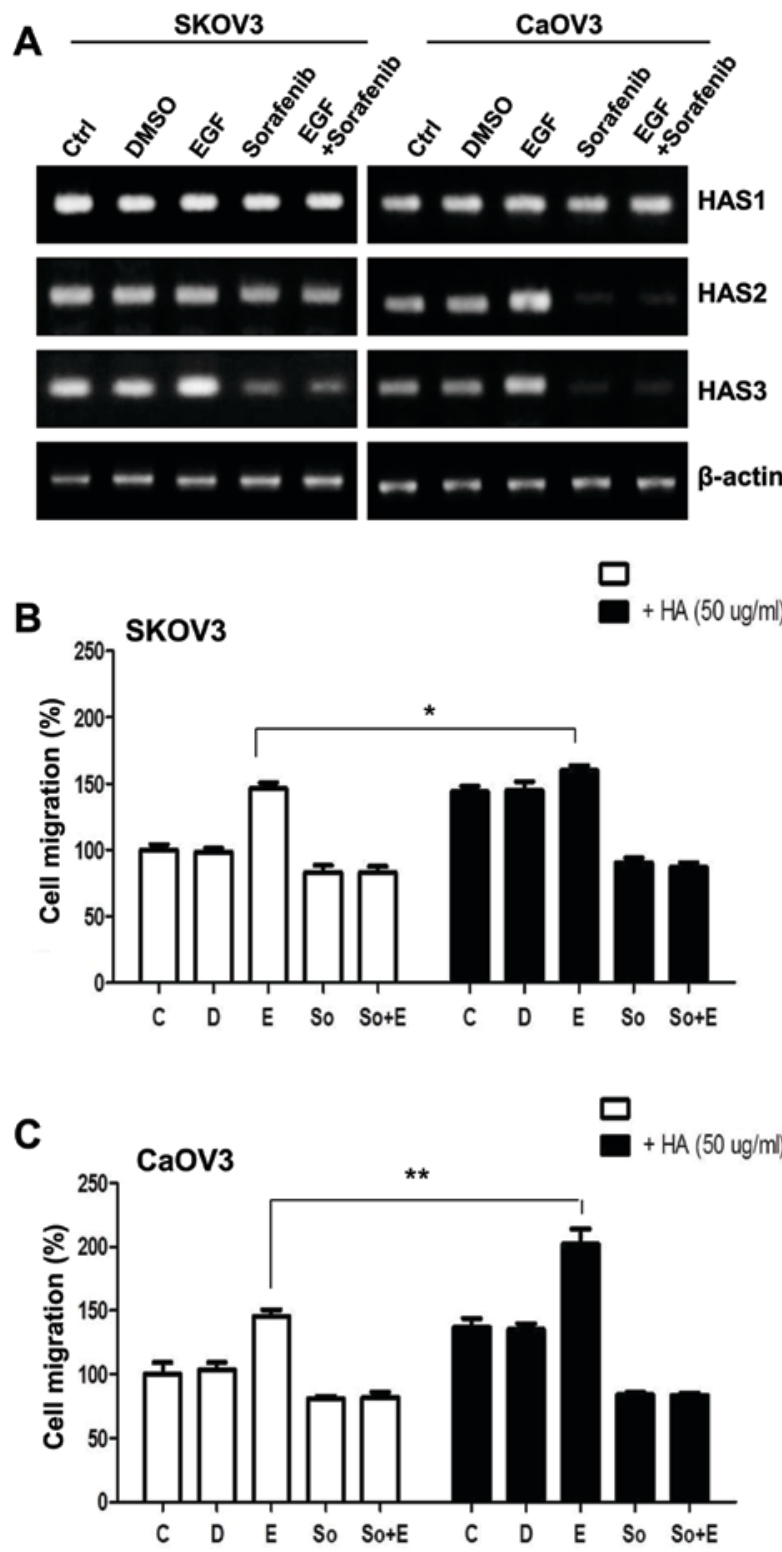

Figure 3. Effects of HA on the migratory activity of EGF-activated ovarian cancer cells. (A) mRNA expression levels of HAS1, HAS2 and HAS3 in EGF-treated SK-OV-3 and Caov-3 cells were assessed using reverse transcription-polymerase chain reaction. (B and C) Migratory capabilities of EGF-stimulated ovarian cancer cells were calculated and plotted as percentage of migration following treatment with HA. Data are expressed as the mean \pm standard error of the mean. ${ }^{*} \mathrm{P}<0.05,{ }^{* *} \mathrm{P}<0.01$. C, control group; D, DMSO group; E, EGF-treated group; So, sorafenib-treated group; So + E, sorafenib- and EGF-treated group; HA, hyaluronan; EGF, epidermal growth factor; HAS, HA synthase.

with EGFR-expressing cells following treatment with EGF (Fig. 7A). In addition, EGFR silencing abolished the expression of MAPK/ERK kinases in SK-OV-3 cells (Fig. 7B). Treatment with a combination of EGF and HA increased the migratory activity of Caov-3 cells compared with in cells treated with EGF alone (Fig. 7C). Furthermore, CD44 silencing in Caov-3 cells resulted in reduced migratory capabilities compared with in control cells following EGF stimulation (Fig. 7C). Treatment with HA or HA combined with EGF upregulated the expression of CD44 and MAPK/ERK kinases in Caov-3 cells; however, CD44 silencing inhibited the expression of 

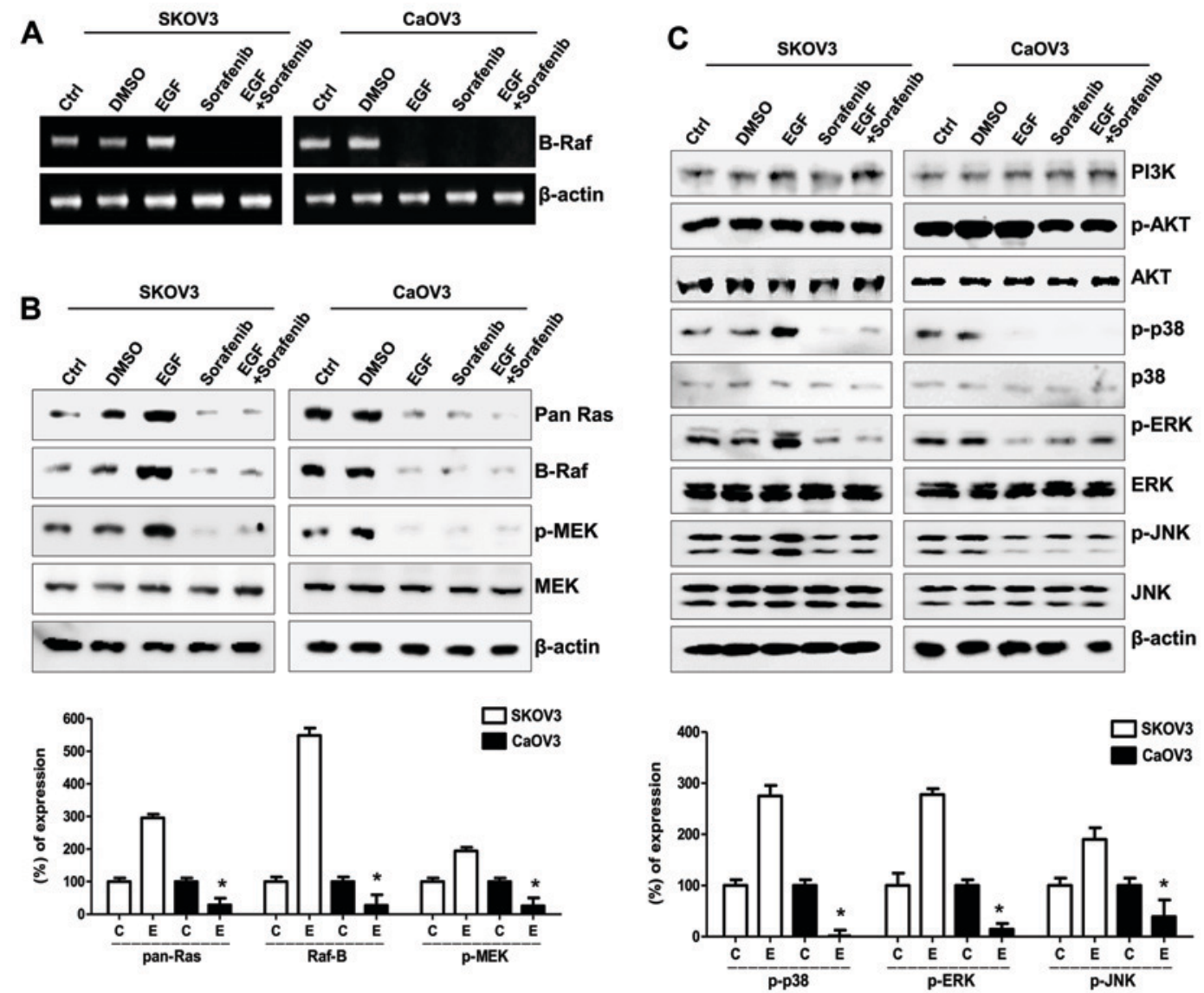

Figure 4. Effects of sorafenib on the MAPK/ERK signaling pathway in ovarian cancer cells following EGF stimulation. (A) Reverse transcription-polymerase chain reaction analysis of B-Raf mRNA expression levels in EGF-treated ovarian cancer cells. (B) Western blot analysis of Ras, Raf, p- and total MEK protein expression levels in EGF-treated ovarian cancer cells. $\beta$-actin served as the loading control. (C) Western blot analysis of EGF-related signaling molecules, including PI3K, p-Akt, total Akt, p-p38, total p38, p-ERK, total ERK, p-JNK and total JNK protein expression levels. Densitometry values of each MAPK and MEK protein were normalized to the total MAPK and MEK protein in the same sample. Densitometry values of Ras and Raf proteins were normalized to $\beta$-actin in the same sample. Data are expressed as the mean \pm standard error of the mean. " $\mathrm{P}<0.05$ EGF-stimulated Caov- 3 vs. SK-OV-3 cells. C, control group; D, DMSO group; E, EGF-treated group; So, sorafenib-treated group; So + E, sorafenib- and EGF-treated group; MAPK, mitogen-activated protein kinase; ERK, extracellular signal-regulated kinase; EGF, epidermal growth factor; p-, phosphorylated; MEK, MAPK/ERK kinase; PI3K, phosphatidylinositol-4,5-bisphosphate 3-kinase; JNK, c-Jun N-terminal kinase.

MAPK/ERK kinases in Caov-3 cells following co-stimulation with EGF and HA (Fig. 7D). These results suggested that MAPK/ERK signaling may be initiated by various molecules in a cell type-dependent manner.

\section{Discussion}

EMT is characterized by the loss of epithelial cell polarity and the acquisition of migratory mesenchymal properties (1). CD44 ${ }^{\text {high }} /$ EGFR $^{\text {low }}$ cell subpopulations in head and neck squamous cell carcinoma have been reported to exhibit a spindle-shaped EMT-like morphology and were resistant to anticancer therapy (23). In addition, it has been reported that CD44 promoted the MMP-dependent activation of EGFR and the EGFR-dependent migration of fibroblasts (24). Tumor-specific HA accumulation has been observed in several types of human cancer, including colon (25) and breast (26). HA has been demonstrated to interact with CD44 to regulate cellular proliferation and motility (27) and to induce MMP-9 secretion (28). Although CD44/HA signaling has been implicated in the promotion of cellular motility, the mechanisms underlying its involvement in EGF-stimulated ovarian cancer have yet to be elucidated.
In the present study, EGF/EGFR signaling was revealed to induce mesenchymal morphology and potentiate the migratory activity of ovarian cancer cells. Conversely, treatment with sorafenib prevented the migration of EGF-treated SK-OV-3 cells, through inhibition of the MAPK/ERK signaling pathway. Raf expression in EGF-treated Caov-3 cells appeared to be reduced; however, sorafenib efficiently blocked cancer cell motility following EGF stimulation. CD44 and HAS levels in EGF-stimulated Caov-3 cells were also downregulated following treatment with sorafenib. Treatment with HA was demonstrated to activate the MAPK/ERK pathway in Caov-3 cells. The present results suggested that the activation of EMT processes involved in ovarian cancer metastasis may be associated with various mechanisms and may depend on cell type. Furthermore, EGF stimulation may contribute to the induction of mesenchymal phenotypes in primary ovarian cancer, through the regulation of HA production and CD44/HA-mediated MAPK/ERK signaling.

EGF requires EGFR and CD44 to exert its effects on cellular proliferation and motility (12). CD44/HA stimulation has been reported to decrease the expression of E-cadherin, and to 

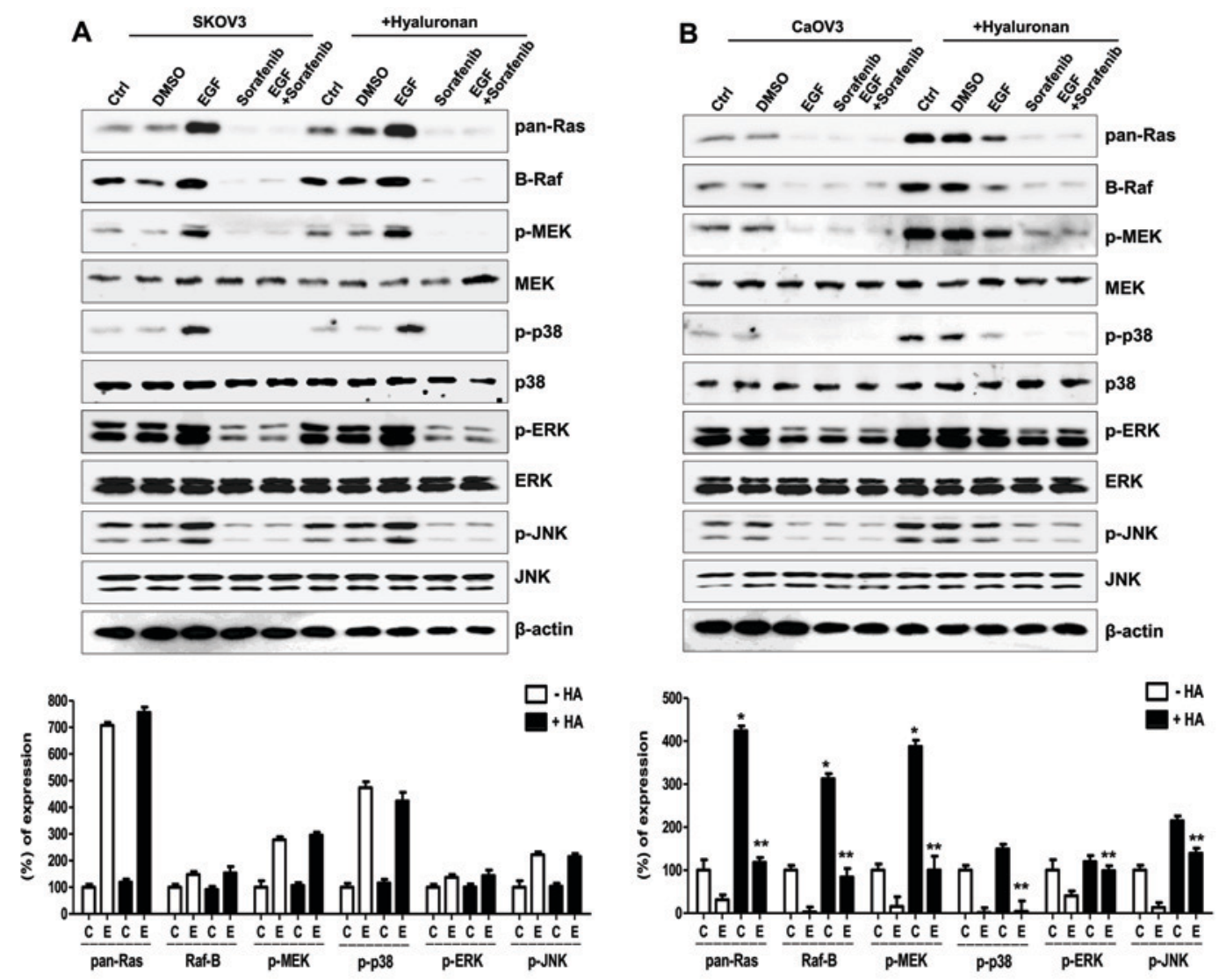

Figure 5. Effects of HA on the MAPK/ERK signaling pathway in EGF-activated ovarian cancer cells. Expression of Ras/Raf/MEK signaling molecules and sequential activation of MAPK following treatment with HA in EGF-activated (A) SK-OV-3 and (B) Caov-3 cells. Densitometry values of MAPK and MEK proteins were normalized to the total MAPK and MEK protein in the same sample. Densitometry values of Ras and Raf proteins were normalized to $\beta$-actin in the same sample. Data are expressed as the mean \pm standard error of the mean. ${ }^{* * *} \mathrm{P}<0.001$ vs. non-HA-treated C group; ${ }^{*} \mathrm{P}<0.05$ vs. non-HA-treated E group. C, control group; D, DMSO group; E, EGF-treated group; So, sorafenib-treated group; So + E, sorafenib- and EGF-treated group; HA, hyaluronan; MAPK, mitogen-activated protein kinase; ERK, extracellular signal-regulated kinase; EGF, epidermal growth factor; MEK, MAPK/ERK kinase; JNK, c-Jun N-terminal kinase; p-, phosphorylated.

increase the expression of Snail, vimentin and N-cadherin (10). Previous studies have demonstrated that CD147 is expressed in invasive areas and proliferative regions and has pleiotropic functions, including inducing MMP synthesis in the stroma and tumor, contributing to drug resistance, and promoting the migration and invasion of tumor cells $(29,30)$. CD147 has also been reported to promote the synthesis of the large extracellular polysaccharide HA and potentiate EGFR/Ras/ERK signaling in a CD44/HA-dependent manner (13). Increased HA and CD44 levels have been correlated with enhanced malignancy in various types of cancer cells in vitro and in vivo $(31,32)$. Increased ERK activation has also been associated with local aggressiveness in vitro and in vivo, and enhanced CD44 transcription (14). The inhibition of MEK, upstream of ERK1/2, has been revealed to decrease CD44 expression and promoter activity, and to reduce cellular migration and invasion (14), whereas ERK1/2 has been demonstrated to promote metastasis via inducing Slug, Snail and EMT (33). The present study examined the relationship between EGF and CD44 signaling in the regulation of cellular migration and invasion using sorafenib. Treatment of SK-OV-3 cells with sorafenib suppressed EGF-mediated CD44 expression and MAPK/ERK signaling. In addition, sorafenib suppressed the mesenchymal phenotype and the invasive capabilities of EGF-stimulated Caov-3 cells; however, EGF stimulation abolished the expression of Raf mRNA and Ras/Raf/MEK proteins. These results suggested that EGF stimulation may trigger various signaling pathways to promote ovarian cancer cell migration in a cell type-specific manner.

Previous studies have reported that the expression of HAS1, HAS2, and HAS3 increased during embryonic development and malignant progression (34), whereas epithelial HAS2 overexpression induced the transition of epithelial cells to fibroblastic and migratory phenotypes (35). However, the role of EGF in HA synthesis and the implication of different HAS isoforms in ovarian cancer cell migration have yet to be elucidated. The present study demonstrated that treatment with EGF resulted in HAS2 activation; HA treatment exerted a more pronounced effect on the migratory capabilities of EGF-activated Caov-3 cells compared with of EGF-activated SK-OV-3 cells.

Notably, high cell surface HA levels are associated with a less aggressive phenotype of ovarian cancer (36). In addition, increased HA levels ( $>50 \mu \mathrm{g} / \mathrm{ml})$ prior to chemotherapy have been associated with poor prognosis and drug resistance (37). In the present study, MAPK/ERK kinases were upregulated in HA-treated Caov-3 cells. Furthermore, treatment with a combination of EGF and HA potentiated the invasive capabilities and induced expression of MAPK/ERK kinases in Caov-3 cells. Conversely, silencing the expression of CD44 abolished 

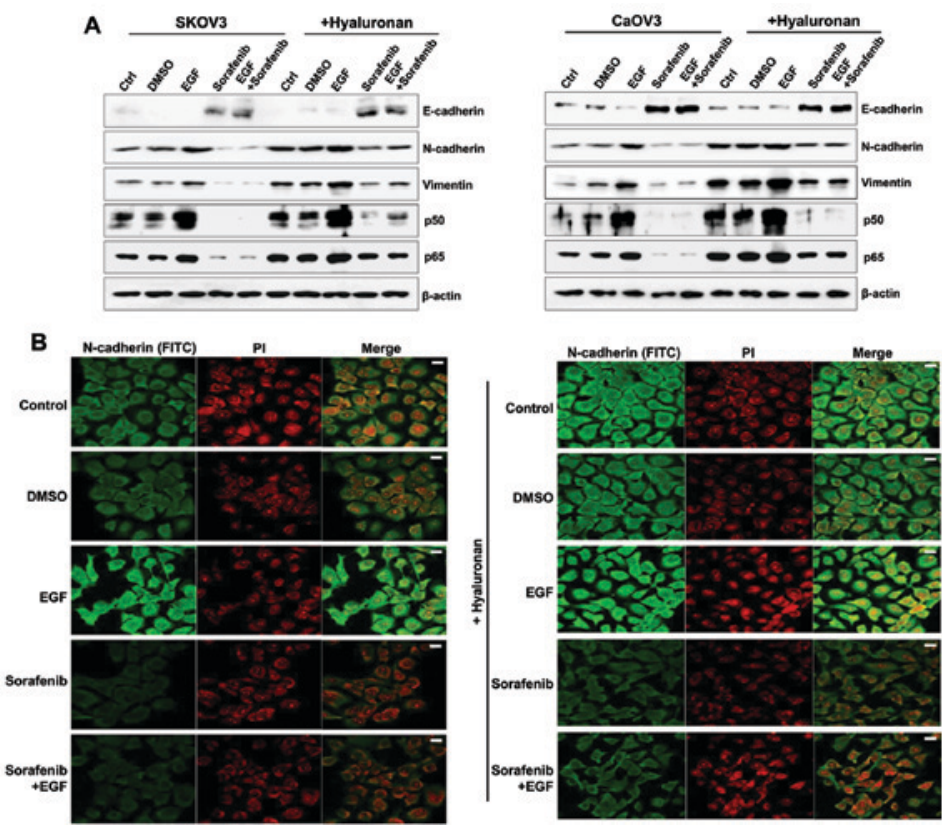

Figure 6. Mesenchymal phenotype enhancement in EGF-treated ovarian cancer cells following HA stimulation. (A) Western blot analysis was used to assess protein expression levels of E-cadherin, $\mathrm{N}$-cadherin, vimentin and the $\mathrm{p} 50 / \mathrm{p} 65 \mathrm{NF}-\mathrm{\kappa B}$ subunits. $\beta$-actin served as the loading control. (B) Immunofluorescence was used to visualize Caov-3 cells. Photomicrographs were captured using a confocal microscope under x 200 magnification. The treated cells were incubated with an anti-N-cadherin antibody for $24 \mathrm{~h}$, which was followed by incubation with a FITC-labeled secondary antibody (shown in green). The nucleus was stained with PI and is presented in red. Scale bars, $20 \mu \mathrm{m}$. The results are representative of three independent experiments. C, control group; D, DMSO group; E, EGF-treated group; So, sorafenib-treated group; So + E, sorafenib- and EGF-treated group; EGF, epidermal growth factor; HA, hyaluronan; NF, nuclear factor; FITC, fluorescein isothiocyanate; PI, propidium iodide.

A

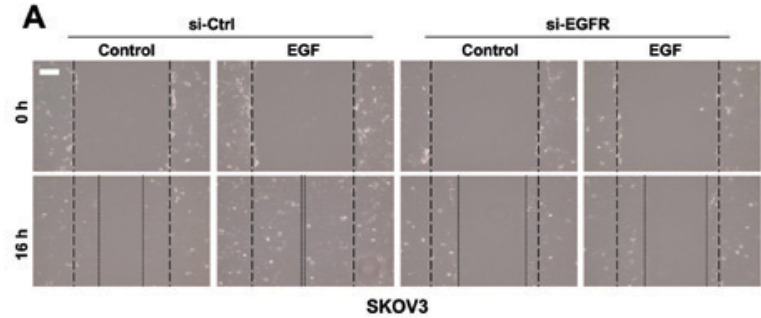

B

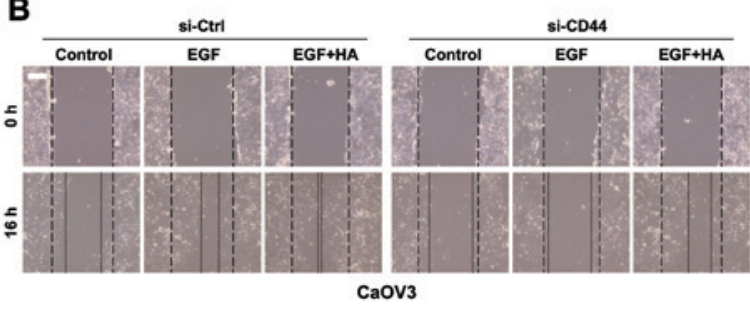

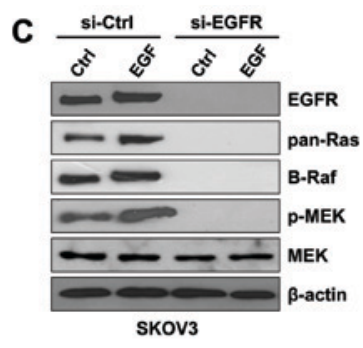

D

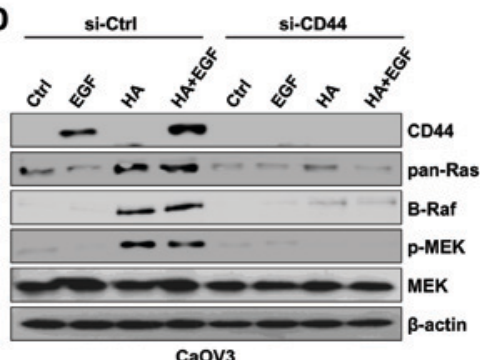

Figure 7. Downregulation of EGFR and CD44 with siRNA inhibited the migration of ovarian cancer cells. (A) SK-OV-3 cells were treated with si-EGFR or si-Ctrl and EGF for $16 \mathrm{~h}$. Migratory capabilities were analyzed using a wound healing assay. (B) Protein expression levels of Ras, Raf, p-MEK and total MEK were assessed using western blot analysis in SK-OV-3 cells. (C) Caov-3 cells were treated with si-CD44 or si-Ctrl and EGF or EGF combined with HA for $16 \mathrm{~h}$. Migratory capabilities were analyzed using a wound healing assay. (D) Protein expression levels of Ras, Raf, p-MEK and total MEK were assessed using western blot analysis in Caov-3 cells. $\beta$-actin served as the loading control. Photomicrographs were captured at x100 magnification using a digital camera under an inverted phase-contrast microscope. Scale bars, $100 \mu \mathrm{m}$. Results are representative of three independent experiments. EGF, epidermal growth factor; EGFR, EGF receptor; CD, cluster of differentiation; si, small interfering; Ctrl, control; p-, phosphorylated; MEK, mitogen-activated protein kinase/extracellular signal-regulated kinase kinase; HA, hyaluronan.

activation of the MAPK/ERK pathway. Therefore, it may be hypothesized that EGF can collaborate with HA to regulate the migration and invasion of primary ovarian cancer cells, through the regulation of MAPK/ERK-mediated signaling pathways.
HA binding to CD44 has been demonstrated to activate NF- $\mathrm{KB}$ through Ras (38), whereas treatment with sorafenib suppressed tumor growth via inhibiting the activation of NF- $\mathrm{BB}$ (39). In the present study, treatment with sorafenib prevented the activation of NF- $\mathrm{\kappa B}$ in EGF-stimulated and 
EGF/HA-co-stimulated ovarian cancer cells. It has previously been reported that the MAPK/ERK pathway was activated via Ras and B-Raf, predominantly in ovarian tumors with low malignant potential (40). Since sorafenib can inhibit the c-Raf and B-Raf kinases that participate in the MAPK/ERK pathway, it is currently being used in combination with platinum and taxane-based chemotherapy or as a single agent for the treatment of patients with ovarian cancer (41).

In conclusion, the present results suggested that HA binding to CD44 may activate the MAPK/ERK signaling pathway during EGF stimulation, whereas sorafenib, in combination with a standard chemotherapeutic agent, may hold potential as a therapeutic strategy for the prevention of CD44/HA-dependent metastasis of primary ovarian cancer.

\section{Acknowledgements}

The present study was supported by the Basic Science Research Program of the Ministry of Education (grant no. NRF-2015R1D1A1A01056672) and Ministry of Science, ICT \& Future Planning (grant no. NRF-2015R1C1A2A01053732) through the National Research Foundation (NRF) of the Republic of Korea.

\section{References}

1. Heppner G, Yamashina K, Miller B and Miller F: Tumor heterogeneity in metastasis. Prog Clin Biol Res 212: 45-59, 1986.

2. Jemal A, Bray F, Center MM, Ferlay J, Ward E and Forman D: Global cancer statistics. CA Cancer J Clin 61: 69-90, 2011.

3. Gadducci A, Sartori E, Maggino T, Zola P, Landoni F, Fanucchi A, Palai N, Alessi C, Ferrero AM, Cosio S and Cristofani R: Analysis of failures after negative second-look in patients with advanced ovarian cancer: An Italian multicenter study. Gynecol Oncol 68: 150-155, 1998.

4. Bagnato A and Rosanò L: Epithelial-mesenchymal transition in ovarian cancer progression: A crucial role for the endothelin axis. Cells Tissues Organs 185: 85-94, 2007.

5. Salomon DS, Brandt R, Ciardiello F and Normanno N: Epidermal growth factor-related peptides and their receptors in human malignancies. Crit Rev Oncol Hematol 19: 183-232, 1995.

6. Auersperg N, Wong AS, Choi KC, Kang SK and Leung PC: Ovarian surface epithelium: Biology, endocrinology and pathology. Endocr Rev 22: 255-288, 2001.

7. Lafky JM, Wilken JA, Baron AT and Maihle NJ: Clinical implications of the ErbB/epidermal growth factor (EGF) receptor family and its ligands in ovarian cancer. Biochim Biophys Acta 1785: 232-265, 2008.

8. Lassus H, Sihto H, Leminen A, Joensuu H, Isola J, Nupponen NN and Butzow R: Gene amplification, mutation, and protein expression of EGFR and mutations of ERBB2 in serous ovarian carcinoma. J Mol Med (Berl) 84: 671-681, 2006.

9. Nagano $\mathrm{O}$ and Saya $\mathrm{H}$ : Mechanism and biological significance of CD44 cleavage. Cancer Sci 95: 930-935, 2004.

10. Kim Y, Lee YS, Choe J, Lee H, Kim YM and Jeoung D: CD44-epidermal growth factor receptor interaction mediates hyaluronic acid-promoted cell motility by activating protein kinase $\mathrm{C}$ signaling involving Akt, Racl, Phox, reactive oxygen species, focal adhesion kinase and MMP-2. J Biol Chem 283 22513-22528, 2008.

11. Murai T, Miyauchi T, Yanagida T and Sako Y: Epidermal growth factor-regulated activation of Rac GTPase enhances CD44 cleavage by metalloproteinase disintegrin ADAM10. Biochem J 39: 65-71, 2006.

12. Ellis IR, Schor AM and Schor SL: EGF AND TGF-alpha motogenic activities are mediated by the EGF receptor via distinct matrix-dependent mechanisms. Exp Cell Res 313: 732-741, 2007.

13. Grass GD, Tolliver LB, Bratoeva M and Toole BP: CD147, CD44, and the epidermal growth factor receptor (EGFR) signaling pathway cooperate to regulate breast epithelial cell invasiveness. J Biol Chem 288: 26089-26104, 2013.
14. Judd NP, Winkler AE, Murillo-Sauca O, Brotman JJ, Law JH, Lewis JS Jr, Dunn GP, Bui JD, Sunwoo JB and Uppaluri R: ERK1/2 regulation of CD44 modulates oral cancer aggressiveness. Cancer Res 72: 365-374, 2012.

15. Frémin $C$ and Meloche S: From basic research to clinical development of MEK1/2 inhibitors for cancer therapy. J Hematol Oncol 3: 8, 2010.

16. Wilhelm SM, Carter C, Tang L, Wilkie D, McNabola A, Rong H, Chen C, Zhang X, Vincent P, McHugh M, et al: BAY 43-9006 exhibits broad spectrum oral antitumor activity and targets the RAF/MEK/ERK pathway and receptor tyrosine kinases involved in tumor progression and angiogenesis. Cancer Res 64: 7099-7109, 2004

17. Zhang J, Chen YL, Ji G, Fang W, Gao Z, Liu Y, Wang J, Ding X and Gao F: Sorafenib inhibits epithelial-mesenchymal transition through an epigenetic-based mechanism in human lung epithelial cells. PLoS One 8: e64954, 2013.

18. Yu D, Wolf JK, Scanlon M, Price JE and Hung MC: Enhanced c-erbB-2/neu expression in human ovarian cancer cells correlates with more severe malignancy that can be suppressed by E1A. Cancer Res 53: 891-898, 1993.

19. Buick RN, Pullano R and Trent JM: Comparative properties of five human ovarian adenocarcinoma cell lines. Cancer Res 45: 3668-3676, 1985

20. Yan L, Zucker S and Toole BP: Roles of the multifunctional glycoprotein, emmprin (basigin; CD147), in tumour progression. Thromb Haemost 93: 199-204, 2005.

21. Marieb EA, Zoltan-Jones A, Li R, Misra S, Ghatak S, Cao J, Zucker S and Toole BP: Emmprin promotes anchorage-independent growth in human mammary carcinoma cells by stimulating hyaluronan production. Cancer Res 64: 1229-1232, 2004.

22. Toole BP and Slomiany MG: Hyaluronan, CD44 and Emmprin: Partners in cancer cell chemoresistance. Drug Resist Updat 11: 110-121, 2008.

23. La Fleur L, Johansson AC and Roberg K: A CD44high/EGFRlow subpopulation within head and neck cancer cell lines shows an epithelial-mesenchymal transition phenotype and resistance to treatment. PLoS One 7: e44071, 2012.

24. Grandis JR and Sok JC: Signaling through the epidermal growth factor receptor during the development of malignancy. Pharmacol Ther 102: 37-46, 2004.

25. Kim HR, Wheeler MA, Wilson CM, Iida J, Eng D, Simpson MA, McCarthy JB and Bullard KM: Hyaluronan facilitates invasion of colon carcinoma cells in vitro via interaction with CD44. Cancer Res 64: 4569-4576, 2004.

26. Cook AC, Chambers AF, Turley EA and Tuck AB: Osteopontin induction of hyaluronan synthase 2 expression promotes breast cancer malignancy. J Biol Chem 281: 24381-24389, 2006.

27. Nedvetzki S, Gonen E, Assayag N, Reich R, Williams RO, Thurmond RL, Huang JF, Neudecker BA, Wang FS, Turley EA and Naor D: RHAMM, a receptor for hyaluronan-mediated motility, compensates for CD44 in inflamed CD44-knockout mice: A different interpretation of redundancy. Proc Natl Acad Sci USA 101: 18081-18086, 2004.

28. Kim MS, Park MJ, Kim SJ, Lee CH, Yoo H, Shin SH, Song ES and Lee SH: Emodin suppresses hyaluronic acid-induced MMP-9 secretion and invasion of glioma cells. Int J Oncol 27: 839-846, 2005.

29. Caudroy S, Polette M, Tournier JM, Burlet H, Toole B, Zucker S and Birembaut P: Expression of the extracellular matrix metalloproteinase inducer (EMMPRIN) and the matrix metalloproteinase-2 in bronchopulmonary and breast lesions. J Histochem Cytochem 47: 1575-1580, 1999.

30. Weidle UH, Scheuer W, Eggle D, Klostermann S and Stockinger H: Cancer-related issues of CD147. Cancer Genomics Proteomics 7: 157-169, 2010.

31. Toole BP: Hyaluronan-CD44 interactions in cancer: Paradoxes and possibilities. Clin Cancer Res 15: 7462-7468, 2009.

32. Jacobson A, Rahmanian M, Rubin K and Heldin P: Expression of hyaluronan synthase 2 or hyaluronidase 1 differentially affect the growth rate of transplantable colon carcinoma cell tumors. Int $\mathbf{J}$ Cancer 102: 212-219, 2002.

33. Chen H, Zhu G, Li Y, Padia RN, Dong Z, Pan ZK, Liu K and Huang S: Extracellular signal-regulated kinase signaling pathway regulates breast cancer cell migration by maintaining slug expression. Cancer Res 69: 9228-9235, 2009.

34. Boregowda RK, Appaiah HN, Siddaiah M, Kumarswamy SB, Sunila S, Thimmaiah KN, Mortha K, Toole B and Banerjee Sd: Expression of hyaluronan in human tumor progression. J Carcinog 5: 2, 2006. 
35. Li Y and Heldin P: Hyaluronan production increases the malignant properties of mesothelioma cells. Br J Cancer 85: 600-607, 2001.

36. Tamada Y, Takeuchi H, Suzuki N, Aoki D and Irimura T: Cell surface expression of hyaluronan on human ovarian cancer cells inversely correlates with their adhesion to peritoneal mesothelial cells. Tumour Biol 33: 1215-1222, 2012.

37. Ricciardelli C, Ween MP, Lokman NA, Tan IA, Pyragius CE and Oehler MK: Chemotherapy-induced hyaluronan production: A novel chemoresistance mechanism in ovarian cancer. BMC Cancer 13: 476, 2013.

38. Fitzgerald KA, Bowie AG, Skeffington BS and O'Neill LA: Ras, protein kinase $C$ zeta, and I kappa B kinases 1 and 2 are downstream effectors of CD44 during the activation of NF-kappa B by hyaluronic acid fragments in T-24 carcinoma cells. J Immunol 164: 2053-2063, 2000 .
39. Dudgeon C, Peng R, Wang P, Sebastiani A, Yu J and Zhang L: Inhibiting oncogenic signaling by sorafenib activates PUMA via GSK $3 \beta$ and NF- $\kappa$ B to suppress tumor cell growth. Oncogene 31: 4848-4858, 2012.

40. Kurman RJ, Visvanathan K, Roden R, Wu TC and Shih IeM: Early detection and treatment of ovarian cancer: Shifting from early stage to minimal volume of disease based on a new model of carcinogenesis. Am J Obstet Gynecol 198: 351-356, 2008.

41. Gemignani ML, Schlaerth AC, Bogomolniy F, Barakat RR, Lin O, Soslow R, Venkatraman E and Boyd J: Role of KRAS and BRAF gene mutations in mucinous ovarian carcinoma. Gynecol Oncol 90: 378-381, 2003. 